\title{
Ação coletiva no âmbito da economia solidária e da autogestão
}

\author{
Maria Eugênia Monteiro Castanheira \\ Universidade Federal de Lavras (UFLA)
}

\author{
José Roberto Pereira \\ Universidade Federal de Lavras (UFLA)
}

\section{Ação coletiva no âmbito da economia solidária e da autogestão}

Resumo: Este ensaio traz reflexões sobre as motivações que conduzem a ação coletiva no âmbito da economia solidária e da autogestão, partindo do pressuposto de que, nestas esferas, a ação coletiva se diferencia daquela que se desenvolve nos domínios do capitalismo e daquela que se desenvolve no contexto social das relações tradicionais. Neste sentido, o objetivo deste ensaio é explorar as especificidades teóricas da ação coletiva orientada pelos princípios da economia solidária e da autogestão, tendo como enfoque analítico a teoria da dádiva. Para tanto, procurou-se, de forma articulada e seqüencial, problematizar a economia solidária, evidenciar os elementos constitutivos da autogestão e o aporte teórico da teoria da dádiva. Acredita-se que tais ponderações indicam um campo a ser explorado empiricamente, podendo contribuir para a elaboração de novos estudos e pesquisas sobre este tema.

Palavras-chave: economia solidária, autogestão, teoria da dádiva.

\section{Collective Action in the Realm of Solidarity Economics and Self-Management}

Abstract: This essay reflects on the motivations that lead to collective action in the realm of solidarity economics and self-management, based on the presumption that, in these spheres, collective action is different from that which takes places in the domains of capitalism and that which develops in the social context of traditional relations. In this sense, the purpose of this essay is to explore the theoretical specificities of collective action guided by the principles of solidarity economics and self-management, with an analytical focus on the theory of donation. To do so, it sought to analyze solidarity economics in an articulated and sequential manner, to reveal the constituent elements of self management and the theoretical support for the theory of donation. These considerations indicate that there is much empirical research to do in this field, and such research can contribute to the elaboration of new studies and research about this issue. Key words: solidarity economics, self-management, theory of donation. 


\section{Introdução}

Pensar a respeito da economia solidária e da prática da autogestão é pensar, necessariamente, na ação coletiva e nas motivações que a orientam. A princípio é possível contentar-se apenas com uma explicação economicista, já que tais iniciativas, especialmente no Brasil, estão intimamente relacionadas a situações de exclusão socioeconômica e de precarização do trabalho. Contudo, tanto a economia solidária quanto a autogestão envolvem proposições que rompem com os pressupostos capitalistas, exigindo a adoção de novos conceitos e valores que não se sustentam somente por artifícios econômicos.

No caso desses fenômenos, a ação coletiva ultrapassa o patamar da satisfação de interesses comuns, buscando alcançar algo maior, como o bem-estar social de todos e para todos, o que contrapõe toda a lógica utilitarista preponderante. Diante disso, as relações que se estabelecem não podem se pautar pelos mesmos preceitos racionais da ordem burocrática vigente, ou corre-se o risco de engendrar o que Singer (2002) chama de "formas degeneradas de economia solidária."

$\mathrm{Na}$ medida em que os recursos coercitivos e de maximização dos interesses individuais são eliminados dos arranjos organizacionais, a atividade coletiva necessita que os agentes se apóiem em outras formas de interação. Estas, no âmbito da economia solidária, ocorrem através de uma racionalidade subjetiva que imprime à ação uma dimensão tácita, porém consciente. Toda essa complexidade, que advém da ligação que se estabelece entre os atores, conduz à reflexão acerca da natureza desse vínculo. É a partir daí, portanto, que se deve iniciar qualquer tentativa de revelar as especificidades da ação coletiva que envolvem a economia solidária e a autogestão. Parte-se do pressuposto de que a ação coletiva no âmbito da economia solidária e da autogestão se diferencia daquela que se desenvolve no âmbito capitalista, bem como se diferencia daquela que se desenvolve no contexto social das relações tradicionais. Portanto, o objetivo deste artigo é explorar as especificidades teóricas da ação coletiva orientada pelos princípios da economia solidária e da autogestão, tendo como enfoque analítico a teoria da dádiva.

\section{Problematizando a economia solidária}

A economia solidária é uma formulação elaborada a partir de experiências econômicas significativas que apresentam traços constitutivos de solidariedade, mutualismo, cooperação e autogestão comunitária, conservando uma racionalidade distinta das outras realidades econômicas (RAZETO, 1993). Essa proposta, mais que uma idéia construída a partir de conceitos, reflexões, ou de um conjunto de políticas de combate ao desemprego, é também um movimento iniciado no século 19, expresso principalmente pelo cooperativismo e pelos socialistas utópicos, com destaque para Owen (1773 - 1858), Proudhon (18091865) e os pioneiros de Rochdale (BENINI, 2003).

O projeto coletivo da economia solidária constitui um fenômeno bastante complexo na medida em que a dimensão econômica tende a estar subordinada às demais dimensões - sociais, políticas ou culturais como um meio para a realização das mesmas. Enfatizando práticas e valores pouco experimentados no sistema capitalista, a economia solidária ultrapassa as questões relativas ao mercado de trabalho ou às lacunas deixadas pelo Estado, e define uma nova concepção das esferas econômica e social. Por essa razão, é um equívoco restringir a economia solidária a um setor à parte, o chamado terceiro setor (FRANÇA FILHO, 2002), ou a um tipo de política compensatória, pensada apenas como artifício emergencial para geração de trabalho e renda (BENINI, 2003). Não se trata, também, de colocá-la na condição de adversário aniquilador do mercado, imaginando ingenuamente que ele possa ser abolido. Todavia, enxergar a economia solidária como proposta de um modo de produção implica que cada empreendimento autenticamente solidário e autogestionário pode estar na vanguarda de um processo de transformação social.

A lógica competitiva que move o capitalismo cujo cerne está na propriedade privada dos meios de produção - gera a formação de uma classe de pessoas que não têm meios próprios de produção e que se sustentam vendendo sua força de trabalho aos capitalistas ou ao Estado. Por estabelecer suas bases sobre a propriedade e a gestão coletiva dos meios de produção, a economia solidária contrapõe essa lógica e recusa a divisão da sociedade em uma classe proprietária dominante e uma classe subalterna sem propriedade (SINGER, 2005). Neste sentido, suas experiências indicam a junção das noções de iniciativa e mutualidade e sugerem a inscrição da solidariedade no centro da elaboração coletiva de atividades econômicas (FRANÇA FILHO, 2002).

$\mathrm{Na}$ economia solidária, todos que trabalham no empreendimento detêm posses iguais, com os mesmos direitos de decisão sobre o seu destino. Nela, a situação do trabalhador é o inverso da vivida na empresa capitalista, já que cada membro do grupo é responsável pela gestão, participando plenamente dos resultados alcançados, sejam eles sobras ou prejuízos. Como não há hierarquia, a união consciente e solidária entre os trabalhadores é essencial para o bom funcionamento da organização. De forma geral, o indivíduo passa por uma inversão completa de situação quando deixa de ser assalariado e torna-se associado, pois para o assalariado as escolhas são limi- 
tadas e as resoluções que o afetam são tomadas por superiores em função de razões que ele desconhece. Quando se torna associado, ele passa a ser orientado por uma lógica coletiva, na qual está encarregado de deliberar em conjunto. Cada um é, portanto, responsável por si, mas também, pelos demais, o que expande o conhecimento mútuo dos associados e a importância de seu inter-relacionamento afetivo (SINGER, 2005).

As práticas de economia solidária e seus fundamentos teóricos apontam para uma forma de conceber e realizar a cidadania no e pelo trabalho, por meio dos princípios da solidariedade, da propriedade social ou coletiva dos meios de produção e da conquista de meios voltados para sua viabilidade. Assim, trata-se de uma ação maior do que prover renda e trabalho dignos, uma vez que os elementos solidariedade e gestão coletiva promovem o trabalhador à condição de sujeito nos processos econômicos e produtivos, tornandoo, a um só tempo, sócio, dono e trabalhador, súdito e soberano de seu modo de produzir e viver, negando a força de trabalho como mercadoria (BENINI, 2003).

Contudo, a prática da economia solidária no seio do capitalismo nada tem de natural. Ela exige dos indivíduos que participam dela um comportamento social pautado pela solidariedade e não mais pela competição, embora tenham sido educados pela vida a reservar a solidariedade ao relacionamento com familiares, amigos, companheiros de lutas, enfim, pessoas às quais estão ligadas por laços de afetividade e confiança. Sendo assim, Singer (2005) argumenta que o exercício da economia solidária exige que as pessoas formadas no sistema capitalista passem por um proces-

\section{As práticas de economia soli-}

dária e seus fundamentos teóricos apontam para uma forma de conceber e realizar a cidadania no e pelo trabalho, por meio dos princípios da solidariedade, da propriedade social ou coletiva dos meios de produção e da conquista de meios voltados para sua viabilidade. relacionamento cooperativo entre si. Singer (2005) ressalta que a fórmula dessa visão não pode ser transmitida em termos teóricos, a não ser em linhas gerais e abstratas. Nesse caso, o verdadeiro aprendizado ntece com a prática, pois o comportamento ecooxiste se efetivamente houver esta questão nos remete às especificidades constituição do sujeito, e indispensánel para que os agentes possam aprender o que se espera deles e o que devem esperar dos outros, ocorre a partir da organização do trabalho através de diversas ações que envolvem a ajuda mútua e a tomada de decisão coletiva pelo exercício da autogestão.

\section{Elementos teóricos da autogestão}

O termo 'autogestão', em seu sentido mais amplo, designa o exercício coletivo do poder na concep ção de gestão social presente em várias teorias socialistas (DORNELES, 2007). Na medida em que a heterogestão configura como a forma hegemônica de organização do trabalho na sociedade capitalista, a autogestão desponta como uma negação da burocracia e sua composição que, artificialmente, separa um grupo de comandantes de um grupo de comandados. Sendo assim, a idéia de autogestão, embora não seja iné$\operatorname{dita}^{2}$, pode ser caracterizada como uma inovação (MOTTA apud CANÇADO, 2007).

$\mathrm{Na}$ Conferência Nacional pelo Socialismo Autogestionário, realizada em Lisboa em so de reeducação coletiva, em que todos vivenciem em conjunto a transição da forma competitiva à forma cooperativa de organização. Um indivíduo agindo sozinho de modo cooperativo, em uma sociedade na qual predomina a competição, acaba sendo 'esmagado' economicamente. Da mesma maneira, um indivíduo que age competitivamente, onde predomina a economia solidária, passa a ser visto como egoísta e desleal pelos demais, sendo excluído de seu meio.

A reeducação coletiva, essencial para que a economia solidária alcance os resultados almejados, representa um desafio pedagógico, pois consiste em transformar a visão de cada membro do grupo sobre o funcionamento da economia de mercado e sobre o maio de 1978, a autogestão foi definida como:

[...] a construção permanente de um modelo de socialismo, em que as diversas alavancas do poder, os centros de decisão, de gestão e controle, e os mecanismos produtivos sociais, políticos e ideológicos, se encontram nas mãos dos produtores-cidadãos, organizados livres e democraticamente, em formas associativas criadas pelos próprios produtores-cidadãos, com base no princípio de que toda a organização deve ser estruturada da base para a cúpula e da periferia para o centro, nas quais se implante a vivência da democracia direta, a livre eleição e revogação, em qualquer momento, das 
decisões, dos cargos e dos acordos (NASCIMENTO, 2003, p. 3).

Segundo Nascimento (2003), mais que uma idéia, a autogestão é uma prática, social e política, que resgata a idéia da "experimentação social" de Rosa de Luxemburgo, pois está articulada à proposta das experiências concretas. Conforme este autor, "é agindo coletivamente que as massas aprendem a se autogerir". Sendo assim, a autogestão fundamenta-se a partir das iniciativas coletivas oriundas da sociedade civil, das empresas, bairros ou municipalidades. Pode-se afirmar, portanto, que a sociedade autogestionária é uma sociedade de experimentação social, uma vez que se institui e se constrói por si mesma, como observa Nascimento (2003, p. 5): “A autogestão é um método e uma perspectiva de transformação social. É um movimento, produto da experiência de vitórias e de derrotas; é um amplo processo de experiências em todo o conjunto da vida social."

É importante frisar que os eventos de natureza autogestionária são frutos de iniciativas coletivas, sem as quais essa forma de organização do trabalho ficaria fadada a deixar de existir. Os empreendimentos que se propõem autogestionários "clamam pelo coletivo e com isso podem apontar para práticas mais democráticas e igualitárias" (MARTINS, 1997, p. 36). Pode-se considerar que a autogestão consiste no nível pleno de participação alcançado pelos membros de um grupo, pois cabe a todos determinar objetivos, escolher os meios para alcançá-los e estabelecer as regras do processo. Esse sistema apresenta um modo diferente de organizar o trabalho, não havendo submissão a uma autoridade e nem separação entre comandantes e comandados (CANÇADO, 2007). Sua viabilidade, portanto, está vinculada à posse coletiva dos meios de produção, em que a participação constitui ato que se tem o direito e o dever de exercer.

Com base em Marx e na visão de Erich Fromm, Carvalho (1983) considera que a submissão dos indivíduos a uma dominação burocrática torna-os alheios aos produtos e meios de produção. Ao promover a participação nas discussões e decisões, a autogestão rompe com a alienação do trabalho, fazendo com que os trabalhadores passem por um processo de autoemancipação como grupo e como indivíduos. Carvalho (1983) acredita que a autogestão constitui um sistema de organização democraticamente superior à democracia formal praticada no capitalismo ocidental, pois dá aos indivíduos o poder de tomar decisões relacionadas às áreas mais essenciais de seu próprio interesse. A partir do momento em que adquirem o domínio das suas condições de trabalho, esses indivíduos tornam-se aptos, também, a deter o controle de suas vidas sociais. Logo, não se trata de participar de um poder, mas de ter um poder (MOTTA apud MARTINS, 1997).
Gutierrez (1997) ressalta que essa jornada contém seus desafios, pois se trata de um contraponto à estrutura burocrática hegemônica e às práticas que ela suscita. $\mathrm{O}$ assalariamento, por exemplo, entendido nesse contexto como acesso a direitos de cidadania, contém elementos culturais que dificultam a compreensão de uma proposta autogestionária, na qual a divisão do trabalho entre os que pensam e os que fazem tende a desaparecer. Assim, problemas de disciplina, hierarquia e participação são freqüentemente encontrados durante o processo de adaptação (LIMA, 2004).

Ocorre que, como as demais formas de organização do trabalho, a autogestão possui limitações e deficiências que exigem seu constante aperfeiçoamento. Ela traz consigo uma liberdade e uma flexibilidade não vivenciadas na sociedade capitalista e cria uma situação de interdependência, na qual ações individuais refletem sobre o todo, podendo causar reações diversas entre os membros do grupo (GUTIERREZ, 1997). Nesse sentido, a autogestão demanda o reconhecimento das diferentes subjetividades e a possibilidade de enfrentamentos e debates construtivos, o que pressupõe a instauração de vínculos baseados na confiança e na solidariedade.

\section{A dádiva e a constituição da coletividade}

A dádiva, segundo Godbout (1999, p. 29), constitui elemento inerente a qualquer formação social e deve ser tratada como pressuposto para formação da coletividade. Sua natureza é estabelecer relações através do circuito composto pelos momentos de dar, receber e retribuir, podendo ser definida como "qualquer prestação de bem ou de serviço, sem garantia de retorno, com vistas a criar, alimentar ou recriar os vínculos sociais entre as pessoas."

Em outros termos, a dádiva consiste em algo que é dado espontaneamente - sejam objetos, palavras, gestos - e, ao ser recebido, gera no beneficiário a necessidade moral e a vontade de retribuir. Essa contradádiva, ao ser feita, torna-se uma nova dádiva, que em outro momento será retribuída, e assim sucessivamente. Desencadeia-se, então, um ciclo de circulação de dádivas cujo efeito é o desenvolvimento de vínculos baseados na confiança.

Diferente das civilizações primitivas ${ }^{3}$, analisadas por Marcel Mauss, onde as trocas e os contratos são estabelecidos através das prestações e contraprestações de presentes e regalos, a dádiva não circula em todas as instâncias da sociedade moderna. Atuando de forma periférica nas esferas do Estado e do mercado, que postulam vínculos inscritos em uma lógica utilitarista, a dádiva encontra na socialidade primária o seu espaço 'natural' de circulação, inaugurando e mantendo as relações de pessoa a pessoa ${ }^{4}$, e garantindo, assim, a existência social. 
Conforme Godbout (1999),

[...] nada se pode iniciar ou empreender, crescer e funcionar se não for alimentado pela dádiva. [...] tudo leva a crer - não importa o que digam os sociólogos do interesse e do poder - que as famílias [bem como as relações de amizade e camaradagem que pressupõem reciprocidade e confiança] se dissolveriam instantaneamente se, repudiando as exigências da dádiva e da contradádiva, elas passassem a se assemelhar a uma empresa ou a um campo de batalha. (GODBOUT, 1999, p. 20).

Desse modo, considera-se que, assim como o mercado e o Estado, também a dádiva forma um sistema, que é o sistema social como tal. É o sistema das relações propriamente sociais na medida em que estas são irredutíveis às relações econômicas ou baseadas em contratos formais. Como bem lembra o autor, os seres humanos, antes de ocupar funções econômicas, políticas ou administrativas, são constituídos como pessoas no registro da socialidade primária ${ }^{5}$ (GODBOUT, 1999).

Mas pensar a dádiva como sistema exige, antes de qualquer coisa, romper tanto com as explicações da prática humana propostas pelo utilitarismo, quanto com as diversas exposições que apresentam o ser humano como um egoísta natural e que o vêem como um ser sedento de poder. Godbout (1999) alega que não se pode traduzir a dádiva apenas como interesse e equivalência contábil, centrando-se unicamente na motivação do recebimento. É preciso analisá-la enquanto circuito, sem isolar quaisquer momentos que a constituem. Não se pode, também, como defende Caillé (2002), imaginar que a realidade complexa e paradoxal que envolve a constituição da coletividade possa ser explicada por uma perspectiva holista, supondo que o vínculo social preexista ontologicamente à ação dos sujeitos sociais. Sendo assim, para melhor compreender a natureza da ação coletiva propõe-se empregar a teoria da dádiva como sistema de análise.

A hipótese que Godbout (1999) defende, através da dádiva, é que o desejo de dar é tão importante para o entendimento da ação humana quanto o de receber. Em função disso, as trocas sociais devem ser analisadas não a partir do que circula, mas a partir dos vínculos por onde circula. Consoante, Caillé (2002) ressalta que, ao lado da circulação dos bens e serviços no mercado, e da redistribuição promovida pelo Estado, há um imenso continente socioeconômico onde eles transitam, em primeira instância, através dos mecanismos da dádiva e da contradádiva.

Este autor se refere ao que Godbout chama de "dádiva entre estranhos", característica da sociedade moderna, e que constitui a quarta esfera ${ }^{6}$ do sistema de circulação de coisas, composta por uma diversida- de de grupos comunitários que se associam livremente para prestar serviços. Seriam as igrejas, os sindicatos e as diferentes formas de associação que podem ter ligações com o Estado e com o mercado e ser, por eles, financiados, mas que se distinguem por ter a dádiva "no centro do sistema de circulação das coisas e serviços" (GODBOUT, 1999, p. 81).

Essas organizações têm o caráter de dádiva visto que são criadas livremente, a partir de iniciativas da sociedade civil, tendo como principal finalidade o bemestar social. De acordo com Godbout (1999), elas podem ser agrupadas em duas categorias: organismos beneficentes e grupos de ajuda mútua. No primeiro caso, os serviços prestados são voluntários, sem retorno aparente, já que a retribuição está no próprio ato de dar. No segundo, as ações são baseadas na reciprocidade, estabelecendo a cadeia da dádiva de dar, receber e retribuir, havendo uma responsabilidade de transmitir o que se recebe. Incluem-se, neste último caso, os empreendimentos concernentes à economia solidária.

A ação coletiva relacionada à teoria da dádiva apresenta contornos bastante particulares. O comportamento de quem doa não é altruísta e tampouco utilitarista. Não se dá para receber, mas através de um gesto livre, sincero e espontâneo, perde-se para ganhar. Aposta-se, ou melhor, confia-se na reciprocidade. Trata-se de uma outra lógica que está longe de ser irracional.

Conforme salienta Putnam (2002), indivíduos racionais, porém incapazes de colaborar, tendem a produzir resultados irracionais do ponto de vista coletivo. A cooperação demanda a confiança no outro e a convicção de que se goza do crédito alheio. Assim, a manutenção de relações estáveis - capazes de dispensar a coerção de uma terceira instância - depende da confiança social e de suas fontes: os sistemas de participação cívica e as regras de reciprocidade.

\section{Considerações finais}

O objetivo deste artigo foi explorar as especificidades teóricas da ação coletiva orientada pelos princípios da economia solidária e da autogestão, tendo como enfoque analítico a teoria da dádiva. Analisou-se que as especificidades teóricas entre economia solidária e autogestão são interdependentes e, muitas vezes, comuns. Tais especificidades dizem respeito: à igualdade de direitos e de condições materiais, tendo como condição a coletivização dos meios de produção; à democracia deliberativa, não se manifestando a hierarquia no processo decisório; à condição de sujeito dos indivíduos que participam da ação, pois se considera que são portadores da consciência crítica nos processos sociais, produtivos e econômicos; ao ní- 
vel pleno de participação, sem a divisão do trabalho entre concepção e execução, manifestando-se apenas a coordenação do processo de trabalho como forma cooperativa de organização; aos vínculos sociais baseados na confiança e na solidariedade.

À luz da teoria da dádiva, estas especificidades da economia solidária e da autogestão estão imbricadas no circuito positivo e moderno da dádiva, cuja essência é a reciprocidade da ação orientada por um forte vínculo social. As relações entre os indivíduos formam uma rede de relacionamentos horizontais, de forma orgânica e interdependente, fundamentadas em vínculos modernos de confiança, fortes o suficiente para superar os interesses exclusivamente individuais e utilitaristas.

Tendo em vista estas considerações, pode-ser afirmar que a ação coletiva no âmbito da economia solidária e da autogestão está orientada, fundamentalmente, pela reciprocidade entre os vínculos sociais, sobretudo os de confiança, estabelecidos no processo de trabalho.

Portanto, a perspectiva da dádiva apresenta a reciprocidade como um circuito helicoidal em que o dar é tão importante para o ser humano quanto o receber. Essa concepção teórica permite compreender a existência de outras formas de relação social que não somente aquelas baseadas na afetividade e no parentesco da socialidade primária, ou constituídas a partir do mercado e do Estado, uma vez que no âmbito da economia solidária e da autogestão os vínculos entre estranhos não se valem de recursos coercitivos ou materiais. Ao contrário, as relações se estabelecem por meio de uma reciprocidade voluntária que, baseada na solidariedade, na confiança e na alteridade, permite a autonomia individual sem romper o vínculo com o coletivo.

Pode-se considerar que a dádiva desponta como referência analítica da ação coletiva, permitindo conhecer as suas especificidades sem recorrer às explicações reducionistas do individualismo metodológico e da abordagem holista. Lançando sua luz na direção de um sujeito social integral, essa perspectiva não só institui a natureza dos vínculos que se estabelecem no âmbito da economia solidária e da autogestão, como também possui potencial analítico para expressar como se formam esses vínculos. Assim, a teoria da dádiva, além de resgatar as questões que envolvem a natureza substantiva das relações sociais, eleva a ação coletiva ao patamar de "uma experiência em que a sociedade é vivida como comunidade" (GODBOUT, 1998).

A partir dessas considerações pode-se pensar a elaboração de estudos e pesquisas de campo sobre este tema de modo a contribuir, cientificamente, com a área de ciências sociais aplicadas. Novas pesquisas podem ser realizadas por meio da etnografia das formas culturais de ajuda mútua no Brasil, tais como 'mutirão', 'troca de dias', 'feiras solidárias', dentre outras. Acredita-se, assim como Mauss (2003) que, se em certos momentos, a sociedade ocidental se afastou da dádiva, este afastamento não é definitivo. Em se tratando de dádiva moderna, que permite a socialidade entre estranhos, a etnografia poderia desvendar "a cor local de algo universal, a moral da dádiva" (LANNA, 2000, p. 192). Outros estudos podem ser feitos nesse sentido: redes interorganizacionais de caráter nacional e internacional voltadas para as trocas econômicas solidárias; o chamado 'comércio justo’ em diferentes setores da economia; dentre as diversas possibilidades.

\section{Referências}

BENINI, E. A. Economia solidária, Estado e sociedade civil: um novo tipo de política pública ou uma agenda de políticas públicas? Org \& Demo, UNESP, Marília, n. 4, p. 3-22, 2003.

CAILlÉ, A. Antropologia do dom: o terceiro paradigma. Petrópolis: Editora Vozes, 2002.

CANÇADO, A. C. Autogestão em cooperativas populares: os desafios da prática. Salvador: IES, 2007. (Cadernos do IES, v. 1).

CARVALHO, N. V. Autogestão: o governo pela autonomia. São Paulo: Brasiliense, 1983.

DORNELES, S. B. Autogestão: uma alternativa para o desenvolvimento regional. Disponível em: <http:// www.urisantiago.br/nadri/artigos/texto\%20simone.pdf $>$. Acesso em: 03 mar. 2007

FRANÇA FILHO, G. C. A problemática da economia solidária: um novo modo de gestão pública? In: ENCONTRO DA ASSOCIAÇÃO NACIONAL DOS PROGRAMAS DE PÓS-GRADUAÇÃO EM ADMINISTRAÇÃO, 24, 2002, Florianópolis. Anais... Rio de Janeiro: ANPAD, 2002.

GODBOUT, J. T. Introdução à dádiva. Rev. bras. Ci. Soc.[online], São Paulo, v.13, n.38, p.39-52, 1998. Disponível em: $<$ http://www.scielo.br/scielo.php?script=sci arttext\&pi=S0102-69091998000300002\&lng=en\&nrm=iso $>$. Acesso em: 14 set 2007.

; CAILlÉ, A. O espírito da dádiva. Tradução de Patrice Charles F. X. Wuillaume. Rio de Janeiro: Fundação Getúlio Vargas, 1999.

GUTIERREZ, G. L. Autogestão de empresas: novas experiências e velhos problemas. In: VIEITEZ, C. G. (Org.). A empresa sem patrão. Marília: UNESP, 1997. 
LANNA, M. Nota sobre Marcel Mauss e o ensaio sobre a dádiva. Revista de Sociologia e Política, Curitiba, v. 14, p. 173-194, jun. 2000.

LIMA, J. C. O trabalho autogestionário em cooperativas de produção: o paradigma revisitado. Revista Brasileira de Ciências Sociais. São Paulo, v.19, n. 56, p.45-62, 2004.

MAUSS, M. Ensaio sobre a dádiva: forma e razão da troca nas sociedades arcaicas. In: SOCIOLOGIA E ANTROPOLOGIA. São Paulo: Cosac \& Naify, 2003. p.185314.

MARTINS, L. H. S. Autogestão: sua atualidade, suas dificuldades. In: VIEITEZ, C. G. (Org.). A empresa sem patrão. Marília: UNESP, 1997.

NASCIMENTO, C. A. Autogestão e o "novo cooperativismo”. In: SEMINÁRIO NACIONAL DE AUTOGESTÃO, 2003. Joinville: MTE, DRTSC, 2003.

POLANYI, K. A grande transformação: as origens da nossa época. Rio de Janeiro: Ed. Campus. 2000.

PUTNAM, R. Comunidade e democracia: a experiência da Itália moderna. Rio de Janeiro: Editora FGV, 2002.

RAZETO, L. Economia de solidariedade e organização popular. In: GADOTTI, M.; GUTIERREZ, F. (Org). Educação comunitária e economia popular. São Paulo: Cortez, 1993.p. 34-58.

SINGER, P. A economia solidária como ato pedagógico. In: KRUPPA, S.M.P. (Org.). Economia solidária e educação de jovens e adultos. Brasília: Inep, 2005, p. 11-31.

Introdução à economia solidária. São Paulo: Fundação Perseu Abramo, 2002.

\section{Notas}

1 No sentido oblativo do termo.

2 Proudhon, no século 19, já abordava a questão da autogestão, apesar de não utilizar tal denominação. $\mathrm{O}$ autor francês considerava ideal uma sociedade organizada de forma autônoma nas funções econômicas de produção e nas funções políticas. "A sociedade autogestionária, em Proudhon, é a sociedade organicamente autônoma, constituída de um feixe de autonomias de grupos se autoadministrando, cuja vida exige a coordenação, mas não a hierarquização"(MOTTAapud CANÇADO, 2007, p. 60).

3 A respeito da dádiva nas sociedades primitivas, ver Mauss (2003).
4 Conforme Godbout (1999), a diferença essencial entre as relações sociais primárias (família, amigos, afetos) e as relações sociais secundárias (Estado e mercado) reside no fato de que as primeiras são desejadas por si mesmas, ao passo que as segundas são consideradas um meio para atingir um fim.

5 Deacordocom Caillé(2002,p.8), “[...] antes mesmode produzir bens ou filhos, o que importa em primeiro lugar é construiro laço social", e este se dá através da dádiva.

6 Segundo Polanyi (2000), o sistema de circulação de coisas compõe-se de três esferas: o mercado, o Estado e a instância doméstica.

\section{Maria Eugênia Monteiro Castanheira}

Mestranda do Programa de Pós-Graduação em Administração da Universidade Federal de Lavras (UFLA)

\section{José Roberto Pereira}

Doutor em Sociologia pela Universidade de Brasília Coordenador do Programa de Pós-Graduação em Administração da UFLA

Professor Adjunto do Departamento de Administração e Economia

Universidade Federal de Lavras (UFLA)

Departamento de Administração e Economia Campus Universitário

Caixa Postal 3037

Lavras - Minas Gerais

CEP: 37200-000 